\title{
Cyclodextrin nanosponge-sensitized enantiodifferentiating photoisomerization of cyclooctene and 1,3-cyclooctadiene
}

\author{
Wenting Liang ${ }^{1}$, Cheng Yang ${ }^{* 1}$, Masaki Nishijima ${ }^{1}$, Gaku Fukuhara ${ }^{1}$, \\ Tadashi Mori $^{1}$, Andrea Mele ${ }^{*}$, Franca Castiglione ${ }^{2}$, Fabrizio Caldera ${ }^{3}$, \\ Francesco Trotta ${ }^{*}$ and Yoshihisa Inoue ${ }^{* 1}$
}

\section{Letter}

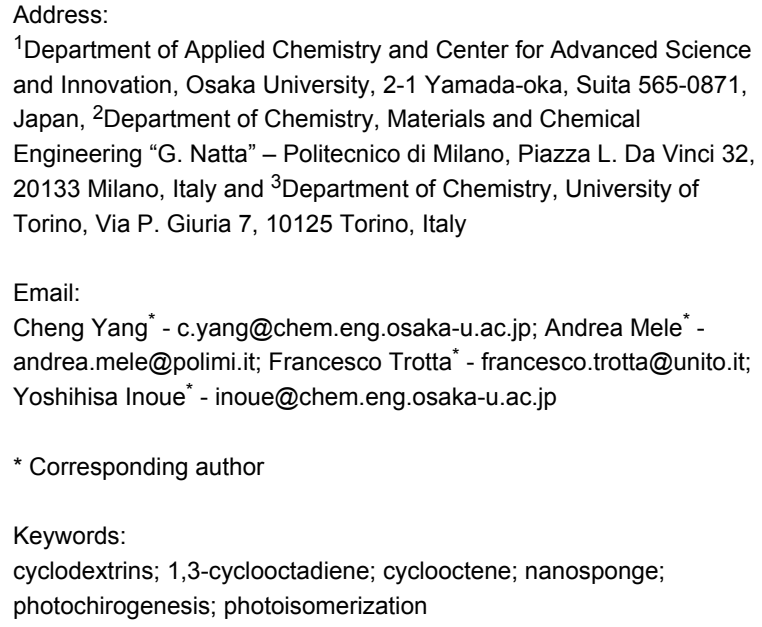

${ }^{1}$ Department of Applied Chemistry and Center for Advanced Science and Innovation, Osaka University, 2-1 Yamada-oka, Suita 565-0871, Japan, ${ }^{2}$ Department of Chemistry, Materials and Chemical Engineering "G. Natta" - Politecnico di Milano, Piazza L. Da Vinci 32, 20133 Milano, Italy and ${ }^{3}$ Department of Chemistry, University of Torino, Via P. Giuria 7, 10125 Torino, Italy

Email:

Cheng Yang* - c.yang@chem.eng.osaka-u.ac.jp; Andrea Mele* andrea.mele@polimi.it; Francesco Trotta ${ }^{*}$ - francesco.trotta@unito.it; Yoshihisa Inoue* - inoue@chem.eng.osaka-u.ac.jp

* Corresponding author

Keywords:

cyclodextrins; 1,3-cyclooctadiene; cyclooctene; nanosponge; photochirogenesis; photoisomerization

Beilstein J. Org. Chem. 2012, 8, 1305-1311.

doi:10.3762/bjoc.8.149

Received: 05 April 2012

Accepted: 27 June 2012

Published: 16 August 2012

This article is part of the Thematic Series "Superstructures with cyclodextrins: Chemistry and applications".

Guest Editor: H. Ritter

(C) 2012 Liang et al; licensee Beilstein-Institut. License and terms: see end of document.

\begin{abstract}
Enantiodifferentiating geometrical photoisomerizations of $(Z)$-cyclooctene and $(Z, Z)$-1,3-cyclooctadiene were performed by using the pyromellitate-linked cyclodextrin network polymer, termed "cyclodextrin nanosponge (CDNS)", as a supramolecular sensitizing host. The photochirogenic behavior of the nanosponges incorporating $\beta$ - or $\gamma$-cyclodextrin was significantly different from that reported for the conventional sensitizer-appended monomeric cyclodextrins, affording chiral $(E)$-cyclooctene and $(E, Z)$ cyclooctadiene in enantiomeric excesses critically dependent on the solution $\mathrm{pH}$ and solvent composition employed, revealing the active roles of chiral void spaces of CDNS in the photochirogenic reaction.
\end{abstract}

\section{Introduction}

The precise control of chiral photoreactions, or photochirogenesis, is one of the most challenging topics in current photochemistry [1-3]. Weak intermolecular interactions, short lifetime and high reactivity of the excited-state substrate are the major causes that prevent efficient asymmetric induction in chiral photochemistry. A supramolecular approach to photochirogenesis provides a convenient and also promising tool to facilitate the excited-state chirality transfer from chiral host to prochiral substrate through the long-lasting intimate supramolecular contacts of guest substrate(s) with the chiral host in 
both the ground and excited states [4-10]. Various types of chiral supramolecular hosts, including modified zeolites [11], hydrogen-bonding templates [12], cyclodextrins [13-21] and serum albumins [22,23], have hitherto been employed to mediate chiral photoreactions. External factors, such as temperature [13], solvent [17], pressure [18] and irradiation wavelength [24], have also been found to play crucial roles in controlling supramolecular photochirogenesis.

Amongst the chiral supramolecular hosts that have been applied to photochirogenesis, cyclodextrin (CD) is undoubtedly the most frequently employed, probably due to its ready availability, modifiability, inherently chiral cavity, and optical transparency down to the UV region [3,4]. Nevertheless, the foregoing studies on CD-based supramolecular photochirogenesis have focused primarily on the use of native and singly or doubly modified monomeric CDs. In this communication, we report the results of the first supramolecular photochirogenesis to use pyromellitate-linked polymeric $\beta$ - and $\gamma$-CDs, termed “cyclodextrin nanosponges" (CDNSs) [25-33], as sensitizing hosts for the enantiodifferentiating photoisomerization of $(Z)$ cyclooctene (1Z) [34-37] and (Z,Z)-1,3-cyclooctadiene (2ZZ) [38-40] (Scheme 1). Enantiodifferentiating photosensitization of $\mathbf{1 Z}$ and $\mathbf{2 Z Z}$ was extensively studied by using different kinds of conventional and supramolecular chiral photosensitizers (Scheme 2). The enantioselectivity obtained is generally low to moderate, despite that fact that some reactions were performed at very low temperatures (below $-100^{\circ} \mathrm{C}$ ).

\section{Results and Discussion}

CDNSs 3, 4 and $\mathbf{5}$ were prepared in almost quantitative yields by reacting pyromellitic dianhydride (PDA) with $\beta-\mathrm{CD}$ or $\gamma-\mathrm{CD}$ in the presence of triethylamine in dimethyl sulfoxide at room temperature (Scheme 1) and purified by extensive Soxhlet extraction with acetone, as reported previously [41]. We termed these cross-linked CD network polymers as "nanosponges", because these CD-based polymers show a nanoporous structure and a property of swelling upon absorption of water. The ability to entrap organic molecules can be ascribed to both the pores generated by the polymerization reaction and to the $\mathrm{CD}$ cavities. Recently, the relationship between the networking properties of $\mathrm{CD}$ nanosponges and the $\mathrm{CD} /$ cross linker ratio employed upon synthesis, was revealed by inelastic light-scattering experiments. Thus, the $\mathrm{CD} /$ cross linker ratio can be conveniently used as a descriptor of the degree of cross linking and the elastic properties [42]. By using Raman and Brillouin scattering experiments, we found that increasing the PMA/CD ratio leads to an increase in the degree of cross linking, with the frequency of the maximum boson peak in cross-polarized Raman spectra shifting to higher wavenumbers. On the other hand, the stiffness of the polymeric network of CDNSs is more affected by the PMA/CD ratio, rather than the type of $\mathrm{CD}$ used.

The adsorption, absorption and inclusion properties of these new materials have been demonstrated for a large variety of substrates, including some pharmaceuticals [25], enzymes [26], pollutants [27], polymers [28], agrochemicals [29], and metal ions [30].

The complexation behavior of $\mathbf{1 Z}$ and $\mathbf{2 Z Z}$ with CDNSs was examined by means of circular dichroism spectroscopy, showing negative induced circular dichroism (ICD) at the ${ }^{1} L_{\mathrm{a}}$ band and more weakly at the ${ }^{1} L_{\mathrm{b}}$ band in aqueous solution (Figure 1a). On the basis of the sector rule proposed by Kajtar et al. $[43,44]$, the pyromellitate (PM) units in the polymer network are deduced to be perching on or shallowly included in the CD cavity, placing the ${ }^{1} L_{\mathrm{a}}$ and ${ }^{1} L_{\mathrm{b}}$ transitions in the negative region (Figure 1c). The addition of $\mathbf{1 Z}$ to the solution of $\mathbf{3}$ caused a small but steady enhancement of the negative ICD (Figure 1b), which is rationalized by assuming that the PM unit is excluded from the cavity to better accommodate guest $\mathbf{1 Z}$ and hence becomes more parallel to the portal plane, inducing

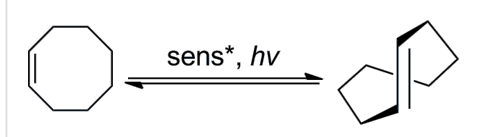

12

$(R)-(-)-1 \mathrm{E}$<smiles>CC1CC=CC=CCC1</smiles>

$2 Z Z$
(R)-(-)-2EZ

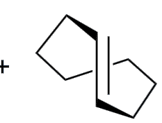

$(S)-(+)-1 E$

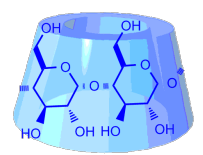

$C D$

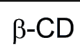

$\beta-C D$

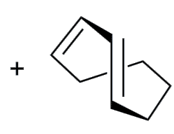

$(S)-(+)-2 E Z \quad \gamma-C D$

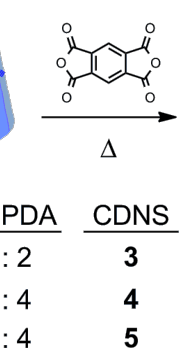

$1: 4 \quad 5$

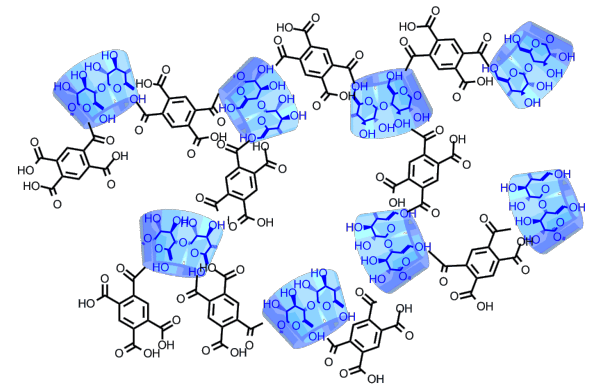

3-5

Scheme 1: Enantiodifferentiating photoisomerizations of $\mathbf{1 Z}$ and $\mathbf{2 Z Z}$ sensitized by $\beta$ - and $\gamma$-cyclodextrin nanosponges (CDNSs) cross linked by pyromellitic dianhydride (PDA). 


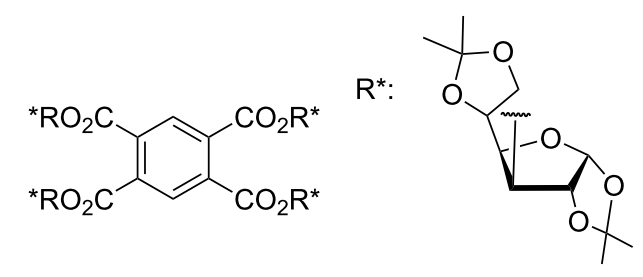

6

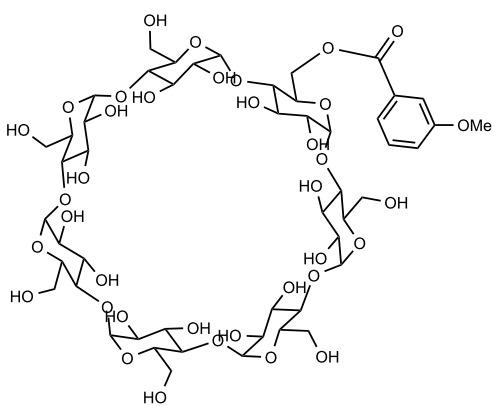

8

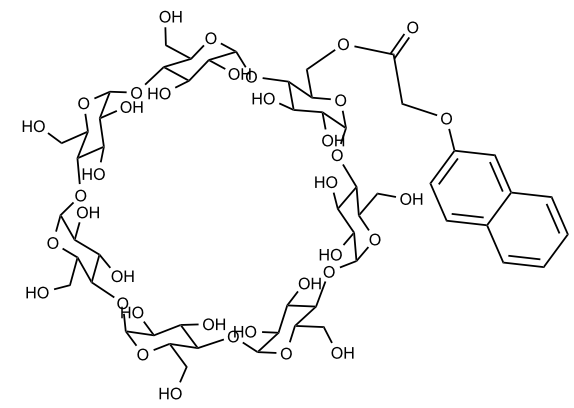

11

9

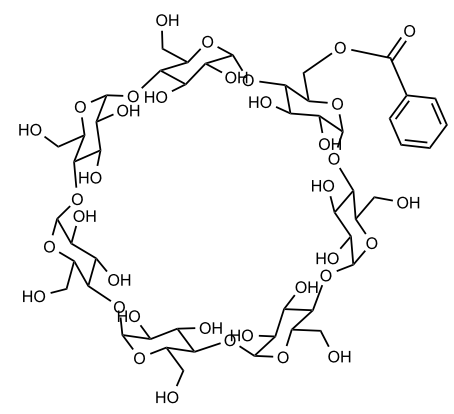

7

$\mathrm{R}^{*}=(-)-1-$ methylheptyl

10

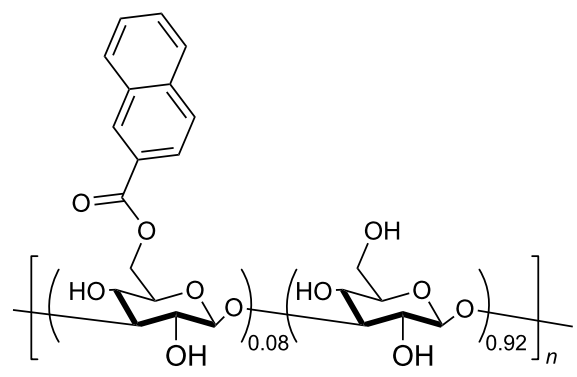

12

\begin{tabular}{llrrl}
\multirow{2}{*}{ substrate } & $\begin{array}{l}\text { chiral } \\
\text { sensitizer }\end{array}$ & $T /{ }^{\circ} \mathrm{C}$ & $\%$ ee & reference \\
\hline \multirow{2}{*}{$\mathbf{2 Z}$} & $\mathbf{6}$ & -110 & 73 & {$[35]$} \\
& 7 & 25 & 11 & {$[9]$} \\
$\mathbf{2 Z Z}$ & $\mathbf{8}$ & -5 & 46 & {$[37]$} \\
& $\mathbf{9}$ in zeolite & 25 & -4.5 & {$[34]$} \\
& 10 & -40 & 17.6 & {$[38]$} \\
& 11 & 0.5 & 4.6 & {$[39]$} \\
& 12 & -160 & 11.7 & {$[40]$}
\end{tabular}

Scheme 2: Representative enantiodifferentiating photosensitization of $\mathbf{1 Z}$ and $\mathbf{2 Z Z}$ with conventional and supramolecular photosensitizers.

stronger ICD at the ${ }^{1} L_{\mathrm{a}}$ band (Figure 1c). Assuming the 1:1 stoichiometry, we calculated the apparent binding constant, averaged over the $\mathrm{CD}$ units of CDNS, as $4000 \mathrm{M}^{-1}$ in water at $25{ }^{\circ} \mathrm{C}$. This value is smaller than those obtained with the sensitizer-modified CDs reported previously [36], for which the steric hindrance in the network polymer and/or the less efficient complexation inside the nanoparticle of CDNS would be responsible. The circular dichroism spectral changes observed for the more cross-linked CDNSs $\mathbf{4}$ and $\mathbf{5}$ upon binding $\mathbf{1 Z}$ or $\mathbf{2 Z Z}$ were too small to allow quantitative evaluation of the binding affinity.

CDNSs 3-5 were dissolved in water to make aqueous solutions with concentrations of $45-60 \mu \mathrm{M}$ in terms of the monomer unit, which were apparently clear at these concentrations but should be a suspension of swollen polymer. In view of the excess 

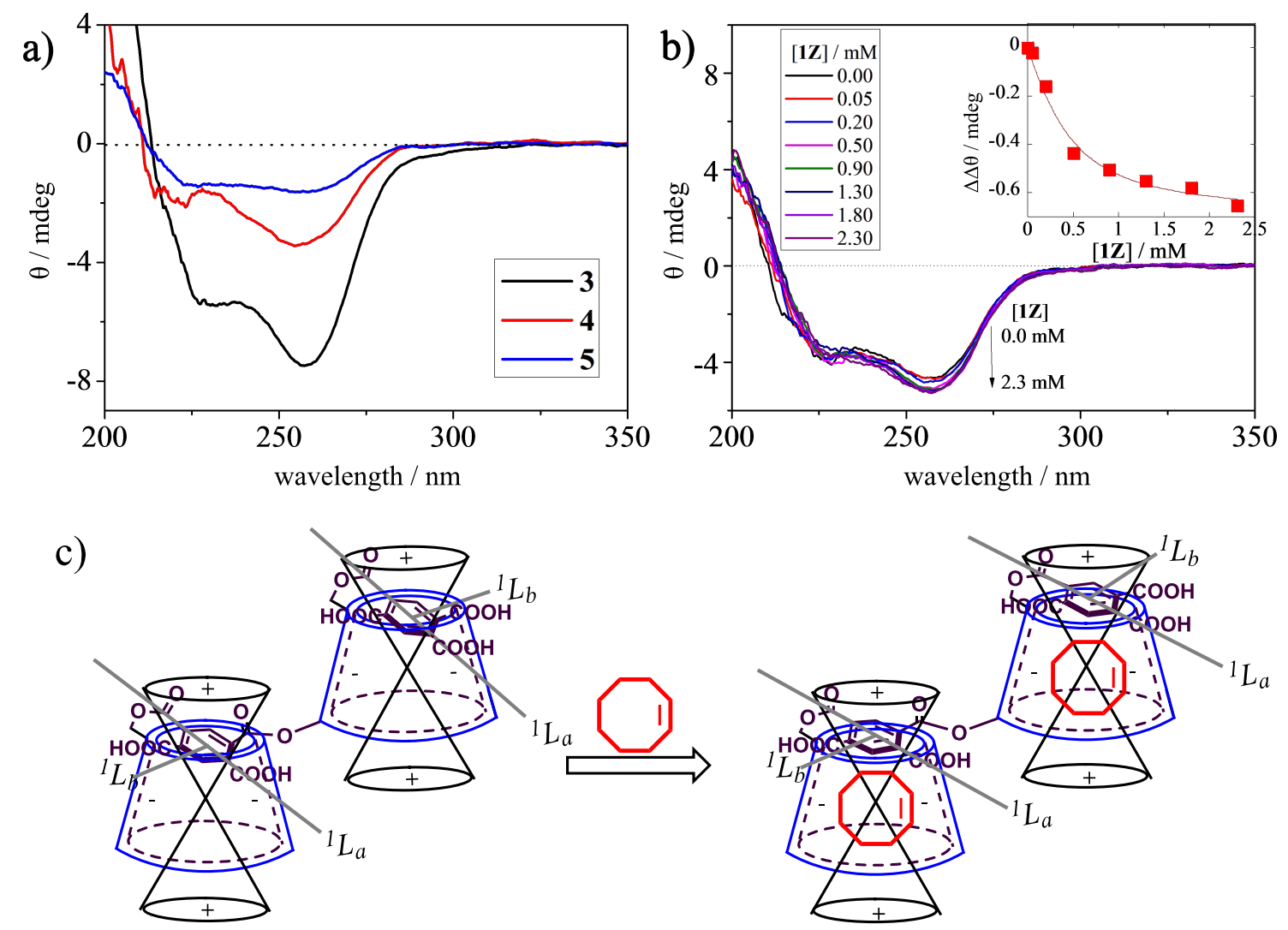

Figure 1: (a) Circular dichroism spectra of $3(67 \mu \mathrm{g} / \mathrm{mL})$ (black), $4(67 \mu \mathrm{g} / \mathrm{mL})$ (red) and $\mathbf{5}(50 \mu \mathrm{g} / \mathrm{mL})$ (blue) in pure water at $25^{\circ} \mathrm{C}$, and (b) of $3(560$ $\mu \mathrm{g} / \mathrm{mL}$ ) in the presence of $0-2.3 \mathrm{mM} \mathrm{1Z}$; Inset shows the nonlinear least-squares curve fit of the ellipticity changes at $257 \mathrm{~nm}$, assuming the $1: 1$ stoichiometry, from which the apparent binding constant was determined to be $4000 \pm 1000 \mathrm{M}^{-1}$. (c) Schematic illustrations of the conformational change of CDNS upon inclusion of $1 Z$.

amount of PDA used in the preparation of CDNSs, it is likely that some of the carboxyl groups in PDA are not incorporated in the polymer chain, and hence, the solution $\mathrm{pH}$ may change the ionic state of the remaining carboxyl groups, affecting the sensi- tizer conformation and also the product selectivity. The conformational change of the $\mathrm{PM}$ units with $\mathrm{pH}$ was examined by circular dichroism spectroscopy. As shown in Figure 2a, increasing the solution $\mathrm{pH}$ caused a significant enhancement of
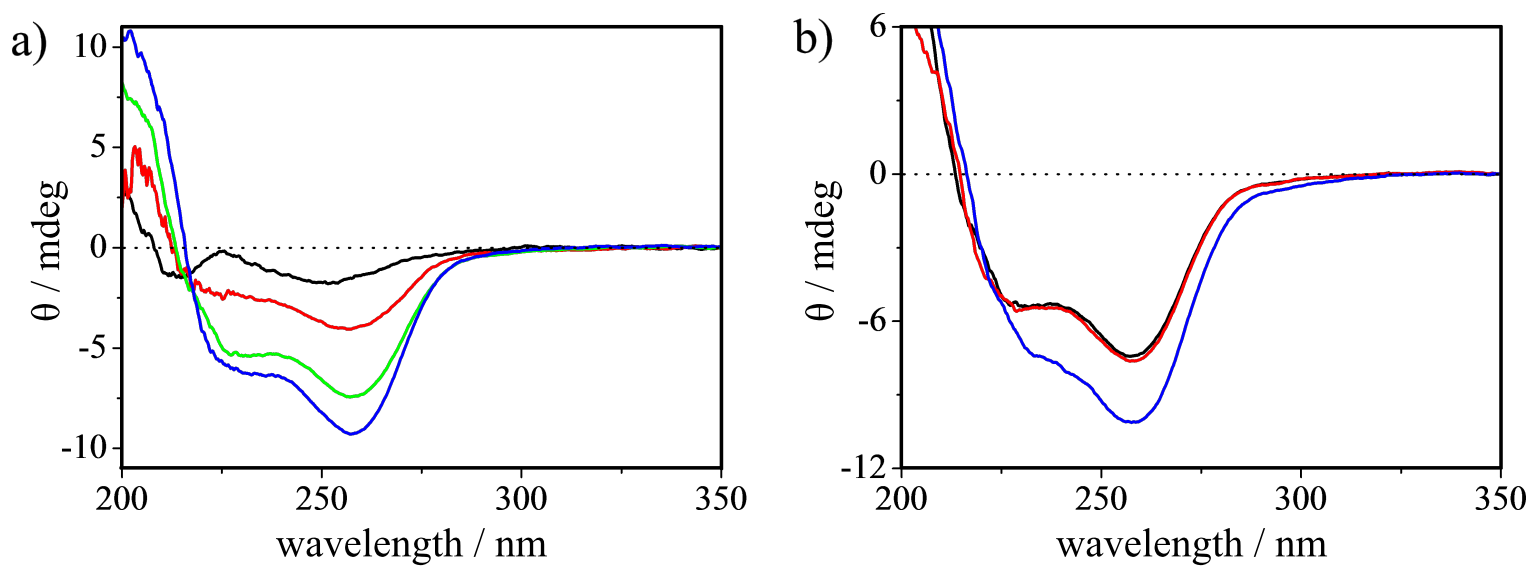

Figure 2: Circular dichroism spectra of $3(67 \mu \mathrm{g} / \mathrm{mL}$ ) (a) in water at $\mathrm{pH} 1.9$ (black), 4.0 (red), 7.5 (green) and 10 (blue) and (b) in water at pH 7.5 (black), in $10 \%$ ethanol (red) and in $50 \%$ ethanol (blue). 
the negative ICD of CDNS 3. This seems reasonable, as the ionization of the carboxylic acid moieties on the PM units $\left(\mathrm{p} K_{\mathrm{a} 1}\right.$ $=2.93$ for pyromellitic acid; $\mathrm{p} K_{\mathrm{a} 1}=2.98$ and $\mathrm{p} K_{\mathrm{a} 2}=5.28$ for phthalic acid) [45] will drive out the shallowly included PM from the cavity but still keep it near the portal with the short ester linker, orienting the ${ }^{1} L_{\mathrm{a}}$ transition in the more negative region of the sector rule (parallel to the portal plane).

Photoisomerizations of $\mathbf{1 Z}$ and $\mathbf{2 Z Z}$ sensitized by CDNSs were performed at $254 \mathrm{~nm}$ under nitrogen in aqueous solutions at different $\mathrm{pH}$ values by using a xenon lamp fitted with a bandpass filter (Asahi Spectra MAX-301). As shown in Table 1, the photosensitizations of $\mathbf{1 Z}$ and $\mathbf{2 Z Z}$ with CDNSs gave $\mathbf{1 E}$ and 2EZ in modest enantioselectivities. Interestingly, the enantiomeric excess (ee) was a critical function of the solution $\mathrm{pH}$. For instance, 3 gave $(+)-\mathbf{1 E}$ in $4.4 \%$ ee at $\mathrm{pH} 1.9$ but a doubled $9.0 \%$ ee at $\mathrm{pH} 10$. The largest $\mathrm{pH}$-induced ee change was observed for $\mathbf{5}$, which afforded (-)-1E in $4.8 \%$ ee at $\mathrm{pH} 6.5$ but antipodal (+)-1E in $9.8 \%$ at $\mathrm{pH} 10$. Similar ee behavior was observed upon photoisomerization of $\mathbf{2 Z Z}$ sensitized by $\mathbf{5}$,

Table 1: Enantiodifferentiating photoisomerization of $\mathbf{1 Z}$ and $\mathbf{2 Z Z}$ sensitized by CDNSs in aqueous solution at different $\mathrm{pH}$ values.

\begin{tabular}{|c|c|c|c|c|}
\hline guest & host & $\mathrm{pH}$ & $E / Z$ & $\%$ ee \\
\hline \multirow[t]{12}{*}{$1 Z$} & $3^{a}$ & 1.9 & 0.03 & +4.4 \\
\hline & & 4.0 & 0.02 & +4.5 \\
\hline & & 7.5 & 0.04 & +7.5 \\
\hline & & 10 & 0.03 & +9.0 \\
\hline & $4^{a}$ & 1.9 & 0.03 & -0.1 \\
\hline & & 4.0 & 0.05 & +1.4 \\
\hline & & 5.2 & 0.07 & +2.1 \\
\hline & & 10 & 0.01 & +4.3 \\
\hline & $5^{a}$ & 1.9 & 0.06 & +0.1 \\
\hline & & 4.0 & 0.09 & +0.6 \\
\hline & & 6.5 & 0.06 & -4.8 \\
\hline & & 10 & 0.01 & +9.8 \\
\hline \multirow[t]{12}{*}{$2 Z Z$} & $3^{a}$ & 1.9 & 0.04 & +5.0 \\
\hline & & 4.0 & 0.04 & +1.7 \\
\hline & & 7.5 & 0.03 & +4.6 \\
\hline & & 10 & 0.01 & +2.7 \\
\hline & $4^{a}$ & 1.9 & 0.02 & +4.0 \\
\hline & & 4.0 & 0.07 & +1.0 \\
\hline & & 5.2 & 0.03 & +4.9 \\
\hline & & 10 & 0.02 & +4.9 \\
\hline & $5^{a}$ & 1.9 & 0.03 & +1.0 \\
\hline & & 4.0 & 0.07 & +1.0 \\
\hline & & 6.5 & 0.13 & +0.7 \\
\hline & & 10 & 0.01 & +7.4 \\
\hline
\end{tabular}

$\mathrm{a}[\mathbf{1 Z}]=[\mathbf{2 Z Z}]=1.5 \mathrm{mM} ;[\mathrm{CDNS}]=0.2 \mathrm{mg} / \mathrm{mL}$; irradiated for $1 \mathrm{~h}$ at $254 \mathrm{~nm}$ in aqueous buffer solutions of $\mathrm{pH} 1.9-10.0$ at $0.5^{\circ} \mathrm{C}$. showing a significant increase from $1.0 \%$ ee at $\mathrm{pH} 1.9-6.5$ to $7.4 \%$ ee at $\mathrm{pH} 10$. These results nicely coincide with the conformational changes of PM units caused by altering the solution $\mathrm{pH}$, providing us with a convenient and also powerful tool for manipulating the stereochemical outcomes of supramolecular photochirogenesis.

It should be noted that $\gamma$-CD-based nanosponge $\mathbf{5}$ gave the highest ee values for both $1 \mathbf{E}$ and $\mathbf{2 E Z}$. This is in sharp contrast to the result reported for the photosensitization with conventional sensitizer-modified CDs $[9,39]$, in which the more sizematched $\beta-C D$, rather than the larger-sized $\gamma-C D$, sensitizers consistently afforded $\mathbf{1 E}$ and $\mathbf{2 E Z}$ in (much) higher ee's. This unusual behavior observed for $\beta$ - and $\gamma$-CDNSs implies the operation of photosensitization and/or enantiodifferentiation mechanisms differing from those proposed for the sensitizermodified monomeric CDs [9,39]. A plausible alternative mechanism, available for the cross-linked CD polymers, is the photosensitization in a chiral void space surrounded by CD and PM units.

In order to obtain experimental support for the alternative mechanism, we examined the solvent effects on the chromophore conformation of CDNS by circular dichroism spectroscopy and also on the CDNS-sensitized photoisomerization. Indeed, the ICD intensity was enhanced upon the addition of ethanol to an aqueous solution of CDNS (Figure 2b), which encouraged us to further investigate the effect of solvent composition on the photoisomerization. As shown in Table 2, the

\begin{tabular}{|c|c|c|c|}
\hline sens* & solvent & $E / Z$ & $\%$ ee \\
\hline \multirow[t]{7}{*}{$3^{a}$} & $\mathrm{H}_{2} \mathrm{O}$ & 0.04 & +7.5 \\
\hline & $5 \% \mathrm{MeOH}$ & 0.07 & +7.8 \\
\hline & $10 \% \mathrm{MeOH}$ & 0.02 & +9.3 \\
\hline & $25 \% \mathrm{MeOH}$ & 0.04 & +9.0 \\
\hline & $50 \% \mathrm{MeOH}$ & 0.04 & +8.5 \\
\hline & $5 \% \mathrm{EtOH}$ & 0.06 & +11.7 \\
\hline & $10 \% \mathrm{EtOH}$ & 0.05 & +9.8 \\
\hline \multirow[t]{4}{*}{$4^{a}$} & $\mathrm{H}_{2} \mathrm{O}$ & 0.07 & +2.7 \\
\hline & $10 \% \mathrm{MeOH}$ & 0.04 & +2.8 \\
\hline & $15 \% \mathrm{MeOH}$ & 0.05 & +3.2 \\
\hline & $25 \% \mathrm{MeOH}$ & 0.02 & +1.5 \\
\hline \multirow[t]{3}{*}{$5^{a}$} & $\mathrm{H}_{2} \mathrm{O}$ & 0.06 & -4.8 \\
\hline & $10 \% \mathrm{MeOH}$ & 0.02 & -4.5 \\
\hline & $25 \% \mathrm{MeOH}$ & 0.01 & -1.6 \\
\hline
\end{tabular}

$\left.\mathrm{a}_{[} \mathbf{1 Z}\right]=1.5 \mathrm{mM}$; [CDNS] $=0.2 \mathrm{mg} / \mathrm{mL}$; irradiated for $30 \mathrm{~min}$ at $254 \mathrm{~nm}$ in distilled water containing a varying amount of methanol or ethanol at $0.5^{\circ} \mathrm{C}$. 
addition of $10 \%$ methanol or $5 \%$ ethanol enhanced the product's ee from 7.5 to 9.8 or $11.7 \%$, respectively, upon sensitization with $\mathbf{3}$, while the further addition of methanol (up to $50 \%$ ) or ethanol (up to $10 \%$ ) led to less pronounced enhancements. In contrast, the ee of $\mathbf{1 E}$ obtained with the more heavily cross-linked $\mathbf{4}$ and $\mathbf{5}$ was not greatly affected or even reduced at high alcohol contents. Crucially, such ee enhancement caused by increasing alcohol content has never been observed for the supramolecular photoisomerization mediated by conventional sensitizer-modified CDs [9], since the addition of alcohol simply reduces the guest affinity $[46,47]$ and hence the ee of the product. This unusual solvent effect upon the addition of alcohol to the aqueous solution of CDNS reinforces the above hypothesis that the enantiodifferentiating photosensitization occurs not in the CD cavity but in the chiral polymer void of CDNS.

\section{Conclusion}

The pyromellitate-linked cyclodextrin nanosponges, employed for the first time as supramolecular reaction media for sensitizing the enantiodifferentiating photoisomerization of $\mathbf{1 Z}$ and $\mathbf{2 Z Z}$, exhibited unique photochirogenesis behavior significantly different from the conventional sensitizer-modified CDs. Thus, the variation of solution $\mathrm{pH}$ and solvent composition enabled us to critically control the stereochemical outcomes, leading to the switching of product chirality and the enhancement of the ee of the product by adding alcohol. The latter result in particular revealed the active roles of chiral voids in CDNS as novel photochirogenic reaction media, encouraging the further application of CDNS to chiral photochemistry.

\section{Acknowledgement}

This work was supported by JST (CY) and JSPS (YI), which are gratefully acknowledged. WL thanks the financial support by the "Global 30" Program (MEXT) at Osaka University.

\section{References}

1. Inoue, Y. Chem. Rev. 1992, 92, 741-770. doi:10.1021/cr00013a001

2. Inoue, Y.; Ramamurthy, V., Eds. Chiral Photochemistry; Marcel Dekker: New York, 2004.

3. Yang, C.; Inoue, Y. Photochirogenesis. In CRC Handbook of Organic Photochemistry and Photobiology, 3rd ed.; Griesbeck, A. G.; Oelgemöller, M.; Ghetti, F., Eds.; Taylor \& Francis: Boca Raton, 2012; pp 125-176.

4. Yang, C.; Inoue, Y. Supramolecular Photochirogenesis. In Supramolecular Photochemistry: Controlling Photochemical Processes; Ramamurthy, V.; Inoue, Y., Eds.; John Wiley \& Sons, Inc.: Hoboken, NJ, 2011; pp 115-154. doi:10.1002/9781118095300.ch4

5. Griesbeck, A. G.; Meierhenrich, U. J. Angew. Chem., Int. Ed. 2002, 41, 3147-3154.

doi:10.1002/1521-3773(20020902)41:17<3147::AID-ANIE3147>3.0.CO ;2-V
6. Yang, C.; Inoue, Y. Supramolecular Photochirogenesis with Cyclodextrin. In Cyclodextrin Materials Photochemistry, Photophysics and Photobiology; Douhal, A., Ed.; Elsevier: Amsterdam, 2006; pp 241-265. doi:10.1016/B978-044452780-6/50012-7

7. Inoue, Y. Nature 2005, 436, 1099-1100. doi:10.1038/4361099a

8. Bauer, A.; Westkämper, F.; Grimme, S.; Bach, T. Nature 2005, 436, 1139-1140. doi:10.1038/nature03955

9. Inoue, Y.; Dong, F.; Yamamoto, K.; Tong, L.-H.; Tsuneishi, H.; Hakushi, T.; Tai, A. J. Am. Chem. Soc. 1995, 117, 11033-11034. doi:10.1021/ja00149a037

10. Lu, R.; Yang, C.; Cao, Y.; Wang, Z.; Wada, T.; Jiao, W.; Mori, T.; Inoue, Y. Chem. Commun. 2008, 374-376. doi:10.1039/b714300a

11. Sivaguru, J.; Natarajan, A.; Kaanumalle, L. S.; Shailaja, J.; Uppili, S.; Joy, A.; Ramamurthy, V. Acc. Chem. Res. 2003, 36, 509-521. doi:10.1021/ar020269i

12. Aechtner, T.; Dressel, M.; Bach, T. Angew. Chem., Int. Ed. 2004, 43, 5849-5851. doi:10.1002/anie.200461222

13. Nakamura, A.; Inoue, Y. J. Am. Chem. Soc. 2003, 125, 966-972. doi:10.1021/ja016238k

14. Nakamura, A.; Inoue, Y. J. Am. Chem. Soc. 2005, 127, 5338-5339. doi:10.1021/ja050704e

15. Yang, C.; Ke, C.; Liang, W.; Fukuhara, G.; Mori, T.; Liu, Y.; Inoue, Y. J. Am. Chem. Soc. 2011, 133, 13786-13789. doi:10.1021/ja202020x

16. Ke, C.; Yang, C.; Mori, T.; Wada, T.; Liu, Y.; Inoue, Y. Angew. Chem., Int. Ed. 2009, 48, 6675-6677. doi:10.1002/anie.200902911

17. Yang, C.; Fukuhara, G.; Nakamura, A.; Origane, Y.; Fujita, K.; Yuan, D.-Q.; Mori, T.; Wada, T.; Inoue, Y. J. Photochem. Photobiol., A: Chem. 2005, 173, 375-383. doi:10.1016/j.jphotochem.2005.04.017

18. Yang, C.; Nakamura, A.; Fukuhara, G.; Origane, Y.; Mori, T.; Wada, T.; Inoue, Y. J. Org. Chem. 2006, 71, 3126-3136. doi:10.1021/jo0601718

19. Yang, C.; Nakamura, A.; Wada, T.; Inoue, Y. Org. Lett. 2006, 8, 3005-3008. doi:10.1021/ol061004x

20. Yang, C.; Nishijima, M.; Nakamura, A.; Mori, T.; Wada, T.; Inoue, Y. Tetrahedron Lett. 2007, 48, 4357-4360. doi:10.1016/j.tetlet.2007.04.104

21. Yang, C.; Mori, T.; Inoue, Y. J. Org. Chem. 2008, 73, 5786-5794. doi:10.1021/j0800533y

22. Wada, T.; Nishijima, M.; Fujisawa, T.; Sugahara, N.; Mori, T.; Nakamura, A.; Inoue, Y. J. Am. Chem. Soc. 2003, 125, 7492-7493. doi:10.1021/ja034641g

23. Nishijima, M.; Wada, T.; Mori, T.; Pace, T. C. S.; Bohne, C.; Inoue, Y. J. Am. Chem. Soc. 2007, 129, 3478-3479. doi:10.1021/ja068475z

24. Wang, Q.; Yang, C.; Ke, C.; Fukuhara, G.; Mori, T.; Liu, Y.; Inoue, Y. Chem. Commun. 2011, 47, 6849-6851. doi:10.1039/c1cc11771h

25. Trotta, F. Cyclodextrin Nanosponges and Their Applications. In Cyclodextrins in Pharmaceutics, Cosmetics, and Biomedicine: Current and Future Industrial Applications; Bilensoy, E., Ed.; John Wiley \& Sons, Inc.: Hoboken, NJ, 2011; pp 323-342. doi:10.1002/9780470926819.ch17

26. Di Nardo, G.; Roggero, C.; Campolongo, S.; Valetti, F.; Trotta, F.; Gilardi, G. Dalton Trans. 2009, 6507-6512. doi:10.1039/b903105g 27. Li, D. Q.; Ma, M. CHEMTECH 1999, 29, 31-37.

28. Alongi, J.; Poskovic, M.; Frache, A.; Trotta, F. Carbohydr. Polym. 2011, 86, 127-135. doi:10.1016/j.carbpol.2011.04.022

29. Seglie, L.; Martina, K.; Devecchi, M.; Roggero, C.; Trotta, F.; Scariot, V. Plant Growth Regul. 2011, 65, 505-511. doi:10.1007/s10725-011-9621-y 
30. Berto, S.; Bruzzoniti, M. C.; Cavalli, R.; Perrachon, D.; Prenesti, E.; Sarzanini, C.; Trotta, F.; Tumiatti, W.

J. Inclusion Phenom. Macrocyclic Chem. 2007, 57, 637-643. doi:10.1007/s10847-006-9270-3

31. Castiglione, F.; Crupi, V.; Majolino, D.; Mele, A.; Panzeri, W.; Rossi, B.; Trotta, F.; Venuti, V. J. Inclusion Phenom. Macrocyclic Chem., in press. doi:10.1007/s10847-012-0106-z

32. Raffaini, G.; Ganazzoli, F.; Mele, A.; Castiglione, F. J. Inclusion Phenom. Macrocyclic Chem., in press. doi:10.1007/s10847-012-0126-8

33. Mele, A.; Castiglione, F.; Malpezzi, L.; Ganazzoli, F.; Raffaini, G.; Trotta, F.; Rossi, B.; Fontana, A.; Giunchi, G. J. Inclusion Phenom. Macrocyclic Chem. 2011, 69, 403-409. doi:10.1007/s10847-010-9772-x

34. Wada, T.; Shikimi, M.; Inoue, Y.; Lem, G.; Turro, N. J. Chem. Commun. 2001, 1864-1865. doi:10.1039/b105381g

35. Inoue, Y.; Tsuneishi, H.; Hakushi, T.; Tai, A. J. Am. Chem. Soc. 1997, 119, 472-478. doi:10.1021/ja963160c

36. Lu, R.; Yang, C.; Cao, Y.; Wang, Z.; Wada, T.; Jiao, W.; Mori, T.; Inoue, Y. Chem. Commun. 2008, 374-376. doi:10.1039/B714300A

37. Lu, R.; Yang, C.; Cao, Y.; Tong, L.; Jiao, W.; Wada, T.; Wang, Z.; Mori, T.; Inoue, Y. J. Org. Chem. 2008, 73, 7695-7701. doi:10.1021/jo801439n

38. Inoue, Y.; Ikeda, H.; Kaneda, M.; Sumimura, T.; Everitt, S. R. L.; Wada, T. J. Am. Chem. Soc. 2000, 122, 406-407. doi:10.1021/ja993542t

39. Yang, C.; Mori, T.; Wada, T.; Inoue, Y. New J. Chem. 2007, 31, 697-702. doi:10.1039/b615353d

40. Fukuhara, G.; Imai, M.; Yang, C.; Mori, T.; Inoue, Y. Org. Lett. 2011, 13, 1856-1859. doi:10.1021/ol2003644

41. Berto, S.; Bruzzoniti, M. C.; Cavalli, R.; Perrachon, D.; Prenesti, E.; Sarzanini, C.; Trotta, F.; Tumiatti, W.

J. Inclusion Phenom. Macrocyclic Chem. 2007, 57, 631-636. doi:10.1007/s10847-006-9273-0

42. Rossi, B.; Caponi, S.; Castiglione, F.; Corezzi, S.; Fontana, A.; Giarola, M.; Mariotto, G.; Mele, A.; Petrillo, C.; Trotta, F.; Viliani, G. J. Phys. Chem. B 2012, 116, 5323-5327. doi:10.1021/jp302047u

43. Kajtar, M.; Horvath-Toro, C.; Kuthi, E.; Szejtli, J. Acta Chim. Acad. Sci. Hung. 1982, 110, 327-333.

44. Berova, N.; Nakanishi, K.; Woody, R. W., Eds. Circular Dichroism: Principles and Applications, 2nd ed.; Wiley-VCH: New York, 2000.

45. Baude, E. A.; Nachod, F. C. Determination of Organic Structures by Physical Methods; Academic Press: New York, 1955.

46. Rekharsky, M. V.; Inoue, Y. Chem. Rev. 1998, 98, 1875-1918. doi:10.1021/cr970015o

47. Inoue, Y.; Yamamoto, K.; Wada, T.; Everitt, S.; Gao, X.-M.; Hou, Z.-J.; Tong, L.-H.; Jiang, S.-K.; Wu, H.-M. J. Chem. Soc., Perkin Trans. 2 1998, 1807-1816. doi:10.1039/a801858h

\section{License and Terms}

This is an Open Access article under the terms of the Creative Commons Attribution License

(http://creativecommons.org/licenses/by/2.0), which permits unrestricted use, distribution, and reproduction in any medium, provided the original work is properly cited.

The license is subject to the Beilstein Journal of Organic Chemistry terms and conditions:

(http://www.beilstein-journals.org/bjoc)

The definitive version of this article is the electronic one which can be found at:

doi:10.3762/bjoc.8.149 